OPEN ACCESS

Edited by:

Qiaobao Zhang,

Xiamen University, China

Reviewed by:

Shuge Dai,

Zhengzhou University, China

Jianglan Shui,

Beihang University, China

Kexin Yao,

King Abdullah University of Science

and Technology, Saudi Arabia

Shuangxi Xing,

Northeast Normal University, China

Limin Jin,

Shenzhen Graduate School of Harbin

Institute of Technology, China

*Correspondence:

Yun Song Yuan

yuan_ys@cqu.edu.cn

Yu Xin Zhang

zhangyuxin@cqu.edu.cn

tThese authors have contributed equally to this work

Specialty section:

This article was submitted to

Nanoscience,

a section of the journal

Frontiers in Chemistry

Received: 15 September 2018

Accepted: 19 December 2018

Published: 17 January 2019

Citation:

Huo WC, Liu XL, Yuan YS, Li N, Lan T,

Liu XY and Zhang YX (2019) Facile

Synthesis of Manganese Cobalt

Oxide/Nickel Cobalt Oxide

Composites for High-Performance

Supercapacitors. Front. Chem. 6:661.

doi: 10.3389/fchem.2018.00661

\section{Facile Synthesis of Manganese Cobalt Oxide/Nickel Cobalt Oxide Composites for High-Performance Supercapacitors}

\author{
Wang Chen Huo ${ }^{1 \dagger}$, Xiao Li Liu ${ }^{1 \dagger}$, Yun Song Yuan ${ }^{2 *}$, Nan $\mathrm{Li}^{3}$, Tian Lan ${ }^{3}$, Xiao Ying Liu ${ }^{4}$ and \\ Yu Xin Zhang ${ }^{1 *}$
}

${ }^{1}$ State Key Laboratory of Mechanical Transmissions, College of Materials Science and Engineering, Chongqing University, Chongqing, China, ${ }^{2}$ College of Urban Construction and Environmental Engineering, Chongqing University, Chongqing, China, ${ }^{3}$ Aerospace Institute of Advanced Materials \& Processing Technology, Beijing, China, ${ }^{4}$ Engineering Research Center for Waste Oil Recovery Technology and Equipment, Ministry of Education, College of Environment and Resources, Chongqing Technology and Business University, Chongqing, China

Transition metal oxides (TMOs) with spinel structures have a promising potential as the electrode materials for supercapacitors application owning to its outstanding theoretical capacity, good redox activity, and eco-friendly feature. In this work, $\mathrm{MnCO}_{2} \mathrm{O}_{4.5} @ \mathrm{NiCO}_{2} \mathrm{O}_{4}$ nanowire composites for supercapacitors has been successfully fabricated by using a mild hydrothermal approach without any surfactant. The morphology and physicochemical properties of the prepared products can be well-controlled by adjusting experimental parameters of preparation. The double spinel composite exhibits a high specific capacitance of $325 \mathrm{~F} \mathrm{~g}^{-1}\left(146 \mathrm{C} \mathrm{g}^{-1}\right)$ and $70.5 \%$ capacitance retention after 3,000 cycling tests at $1 \mathrm{~A} \mathrm{~g}^{-1}$.

Keywords: transition metal oxides, spinel structure, composites, supercapacitor, $\mathrm{MnCo}_{2} \mathrm{O}_{4.5} @ \mathrm{NiCo}_{2} \mathrm{O}_{4}$ nanowire

\section{INTRODUCTION}

The rising concerns about environmental crisis and increasing demand of renewable energy sources have attracted extensive attention for developing a secure, high-performance and sustainable storage technology (Lukatskaya et al., 2016; Zhang et al., 2018a). Recently, various energy storage technologies have emerged, such as lithium ion batteries (Zheng et al., 2018), Li-ion sulfur batteries (Sun et al., 2018) and supercapacitors (Qu et al., 2017) etc. Supercapacitors, also named as electrochemical capacitors (ECs), will be one of the most desirable power devices of next generation, owing to their high power density (Simon and Gogotsi, 2008), rapid charging-discharging rate (Miller and Simon, 2008), and excellent cycle stability (Dai et al., 2018). Various materials have been investigated as electrodes for ECs, such as carbon materials (Zhao et al., 2010; Niu et al., 2013; Zhang et al., 2018b), transition metal oxides (TMOs) (Liu et al., 2012; Nam et al., 2012) and conductive polymers (Lim et al., 2015). Generally, TMOs are superior in specific capacitance and stability. Their specific capacitance is 10 100 times of carbon materials, and they have better stability than conductive polymers. Among the TMOs, the spinel structures, especially spinel ternary TMOs, including the $\mathrm{MnCo}_{2} \mathrm{O}_{4.5}$ ( $\mathrm{Li}$ et al., 2014), $\mathrm{NiCo}_{2} \mathrm{O}_{4}$ (Wang C. et al., 2016), and $\mathrm{ZnCo}_{2} \mathrm{O}_{4}$ (Wu et al., 2015) etc., have been extensively investigated and exhibited an excellent electrochemical performance as electrode materials for ECs, due to its extremely high theoretical specific capacitance, good redox activity, and eco-friendliness (Qiu et al., 2018; Parveen et al., 2019), thus implying that these could be the most potential electrode materials for next-generation ECs. 
Over the past few years, numerous researchers have been devoted to develop new strategies to enhance the electrochemical performance of $\mathrm{NiCo}_{2} \mathrm{O}_{4}$ nanomaterials for ECs electrodes (Sun et al., 2016). For example, Wang C. et al. (2016) reported that the $\mathrm{NiCo}_{2} \mathrm{O}_{4}$ nanoneedle was directly anchored on the $\mathrm{Ni}$ foam and carbon fabrics, respectively, via a facile hydrothermal method following with a calcination process in air. This strategy would enhance the combination of electrode material and substrate for improving the electrical conductivity and facilitating electrochemical performance. Sun et al. (2016) found that the porous $\mathrm{NiCo}_{2} \mathrm{O}_{4}$ nanograss supported on $\mathrm{Ni}$ foam shown a surprisingly high specific capacitance of $807.7 \mathrm{~F} \mathrm{~g}^{-1}$ at $1 \mathrm{~mA}$ $\mathrm{cm}^{-2}\left(0.38 \mathrm{~A} \mathrm{~g}^{-1}\right)$ after suffering the hydrogenation process for $3 \mathrm{~h}$, which is ascribed to the formation of oxygen vacancies in disordered surface layers during the hydrogenation process and enhance the electrical conductivity. And there are many other strategies to improve the agglomeration of nanomaterials and facilitating contacting of electrolyte and electrode to promote the performance, such as $\mathrm{NiCo}_{2} \mathrm{O}_{4} @ 3 \mathrm{DNF}$ framework (Parveen et al.,2019) and $\mathrm{Co}_{9} \mathrm{~S}_{8} @ \mathrm{NiCo}_{2} \mathrm{O}_{4}$ nanobrushes (Liu et al., 2019 ) etc. However, the price of $\mathrm{Ni}$ is eight times than the $\mathrm{Mn}$ (Information comes from the SMM Information \& Technology Co, Ltd.), the high cost severely restricted its commercial applications. Hence, utilizing Mn to substitute Ni or constructing the Mn-Co-O@Ni-Co-O double spinel composites, should be a feasible and effective method for reducing the cost and promoting its application. Unfortunately, the Mn substituted spinel structure always exhibited the poor specific capacitance ( $\mathrm{Li}$ et al., 2014, 2015; Hao et al., 2015; Wang K. et al., 2016). Thus, fabricating the Mn-Co-O@Ni-Co-O double spinel composites would be an alternative preferable strategy, which is not only decreasing the commercial applications cost, but also improving the electrochemical performance of double spinel composites for ECs via utilizing the synergistic effect of the core and shell.

Herein, the core-shell $\mathrm{MnCo}_{2} \mathrm{O}_{4.5} @ \mathrm{NiCo}_{2} \mathrm{O}_{4}$ double spinel structures were successfully synthesized by a facile hydrothermal route without any surfactant, where the core, hierarchical $\mathrm{MnCo}_{2} \mathrm{O}_{4.5}$ nanowires with a diameter of $300 \sim 500 \mathrm{~nm}$ was provided by Li et al. (2015). The prepared $\mathrm{MnCo}_{2} \mathrm{O}_{4.5} @ \mathrm{NiCo}_{2} \mathrm{O}_{4}$ hybrids exhibit a promising electrochemical performance via comparing with literature results of selected samples which have similar components and structures (Table 1) (Wu et al., 2011; Kuang et al., 2014; Li et al., 2014, 2015; Hao et al., 2015; Sun et al., 2016; Wang C. et al., 2016; Wang K. et al., 2016). This strategy not only diminishes the dosage of $\mathrm{Ni}$, but also elevates the electrochemical performance of the double spinel composites for ECs, which are favor of the commercial applications for next generation energy storage devices.

\section{EXPERIMENTAL SECTION}

\section{Materials Synthesis}

$\mathrm{MnCo}_{2} \mathrm{O}_{4.5}$ nanowires provided by Li's group were adopted as the reaction substrates in the experimental. The synthesis procedure of $\mathrm{MnCo}_{2} \mathrm{O}_{4.5}$ has been reported in detail in Li's work (Li et al., 2015). Figure 1 shows the schematic illustration of the $\mathrm{MnCo}_{2} \mathrm{O}_{4.5} @ \mathrm{NiCo}_{2} \mathrm{O}_{4}$ nanowires, and the composites were fabricated as follows: $0.001 \mathrm{~mol} \mathrm{Ni}\left(\mathrm{NO}_{3}\right)_{2} \cdot 6 \mathrm{H}_{2} \mathrm{O}, 0.002 \mathrm{~mol}$ $\mathrm{Co}\left(\mathrm{NO}_{3}\right)_{2} \cdot 6 \mathrm{H}_{2} \mathrm{O}, 0.002 \mathrm{~mol} \mathrm{NH}_{4} \mathrm{~F}$ and $0.005 \mathrm{~mol}$ urea were dissolved in $35 \mathrm{~mL}$ deionized water at room temperature, then $20 \mathrm{mg} \mathrm{MnCo}_{2} \mathrm{O}_{4.5}$ were added into the mixture, supplemented by ultrasonic treatment until the $\mathrm{MnCo}_{2} \mathrm{O}_{4.5}$ powder were dispersed uniformly. Then the suspension was put in the Teflonlined stainless autoclave, sealed and heated at $120^{\circ} \mathrm{C}$ for 6 and $12 \mathrm{~h}$, respectively. After cooling down to room temperature, collected precipitates were washed several times using ethanol and deionized water to remove the attached reaction products and/or residual reactants, then put into the vacuum oven at $60^{\circ} \mathrm{C}$ to dry. Finally, the metal hydroxides were calcined at $350^{\circ} \mathrm{C}$ for $2 \mathrm{~h}$ to convert into metal oxides most likely as described by the following equations (Xu and Wang, 2011):

$$
\begin{gathered}
\mathrm{Ni}^{2+}+2 \mathrm{Co}^{2+}+6 \mathrm{OH}^{-} \rightarrow \mathrm{NiCo}_{2}(\mathrm{OH})_{6} \\
\mathrm{NiCo}_{2}(\mathrm{OH})_{6}+\frac{1}{2} \mathrm{O}_{2} \rightarrow \mathrm{NiCo}_{2} \mathrm{O}_{4}+3 \mathrm{H}_{2} \mathrm{O}
\end{gathered}
$$

\section{Characterization}

X-ray photoelectron spectroscopy (Kratos XSAM800, XPS), the powder X-ray diffraction (D/max 2500, $\mathrm{Cu} K \alpha, \mathrm{XRD})$ and thermosgravimetric analyzer-differential scanning calorimeter (NETZSCH STA 449C, TGA-DSC) were used to characterize the crystallinity and components of prepared materials. Morphological structure was analyzed by scanning electron microscopy (Zeiss Auriga FIB/SEM). The detailed structures of the materials were collected by transmission electron microscopy (FEI TECNAI G2 F20, TEM).

\section{Electrochemical Measurement}

In this work, the three-electrode configuration with the potentiostat/galvanostat model (CHI660E electrochemical workstation) was employed to detect the electrochemical performance of the prepared electrode materials, where nickel foam $(1 \times 1 \mathrm{~cm})$ supported $\mathrm{MnCo}_{2} \mathrm{O}_{4.5} @ \mathrm{NiCo}_{2} \mathrm{O}_{4}$ composites worked as the working electrode, saturated calomel electrode (SEC) served as the reference electrode and platinum plate acted as the counter electrode in $3 \mathrm{M} \mathrm{KOH}$ electrolyte. The materials for the preparation of working electrode are active materials, acetylene black and polyvinylidene difluoride (PVDF) (mass ratio, 7:2:1). After calculation, the net mass of $\mathrm{MnCo}_{2} \mathrm{O}_{4.5} @ \mathrm{NiCo}_{2} \mathrm{O}_{4}$ loaded on each working electrode is $1.5 \mathrm{mg}$.

The cyclic voltammetry (CV) and charge-discharge (GCD) measurements were tested on a CHI660E electrochemical workstation. The CV curves were carried out at disparate scan rates between 0 and $0.5 \mathrm{~V}$ (vs. SCE), while the charge-discharge curves $(0 \sim 0.45 \mathrm{~V}$ vs. SCE) were monitored at different current densities. The electrochemical impedance spectroscopy (EIS) plots were obtained over the frequency from $10^{-2}$ to $10^{5} \mathrm{~Hz}$ with the $5 \mathrm{mV}$ amplitude. The normalized specific capacitance $(C, \mathrm{~F}$ $\left.\mathrm{g}^{-1}\right)$ and $\left(\boldsymbol{Q}, \mathrm{C}^{-1}\right)$ was calculated from charge-discharge curves and following the equation (Dai et al., 2017):

$$
\begin{array}{r}
C=I \Delta t / \Delta V m \\
Q=I \Delta t / m
\end{array}
$$


TABLE 1 | Comparison of specific capacitances of selected literature results obtained from materials with similar components and this work.

\begin{tabular}{|c|c|c|c|c|}
\hline Samples & Electrolyte & Test condition & Cs $\left(F_{g^{-1}}\right)$ & References \\
\hline $\mathrm{MnCO}_{2} \mathrm{O}_{4.5}$ & $1 \mathrm{M} \mathrm{Na}_{2} \mathrm{SO}_{4}$ & $0.5 \mathrm{~A} \mathrm{~g}^{-1}$ & $80.2 \mathrm{~F} \mathrm{~g}^{-1}$ & Li et al., 2015 \\
\hline $\mathrm{MnCO}_{2} \mathrm{O}_{4.5}$ & $1 \mathrm{M} \mathrm{KOH}$ & $1 \mathrm{Ag}^{-1}$ & $118.8 \mathrm{~F} \mathrm{~g}^{-1}$ & Li et al., 2014 \\
\hline $\mathrm{MnCO}_{2} \mathrm{O}_{4.5}$ & $1 \mathrm{M} \mathrm{Na}_{2} \mathrm{SO}_{4}$ & $2 \mathrm{Ag}^{-1}$ & $114 \mathrm{~F} \mathrm{~g}^{-1}$ & Wang C. et al., 2016 \\
\hline Carbon aerogel@MnCo $\mathrm{M}_{4.5}$ & $1 \mathrm{M} \mathrm{Na}_{2} \mathrm{SO}_{4}$ & $0.2 \mathrm{~A} \mathrm{~g}^{-1}$ & $269.9 \mathrm{~F} \mathrm{~g}^{-1}$ & Hao et al., 2015 \\
\hline $\mathrm{NiCo}_{2} \mathrm{O}_{4} @ \mathrm{Ni}$ foam & $6 \mathrm{M} \mathrm{KOH}$ & $1 \mathrm{~mA} \mathrm{~cm}^{-2}$ & $807.7 \mathrm{~F} \mathrm{~g}^{-1}$ & Sun et al., 2016 \\
\hline $\mathrm{NiCO}_{2} \mathrm{O}_{4} @ \mathrm{Ni}$ foam & $2 \mathrm{M} \mathrm{KOH}$ & $1 \mathrm{Ag}^{-1}$ & $655 \mathrm{~F} \mathrm{~g}^{-1}$ & Wang K. et al., 2016 \\
\hline $\mathrm{NiCO}_{2} \mathrm{O}_{4}$ & $2 \mathrm{M} \mathrm{KOH}$ & $1 \mathrm{Ag}^{-1}$ & $372 \mathrm{~F} \mathrm{~g}^{-1}$ & Kuang et al., 2014 \\
\hline $\mathrm{NiCO}_{2} \mathrm{O}_{4}$ & $1 \mathrm{M} \mathrm{KOH}$ & $1 \mathrm{~mA} \mathrm{~cm}{ }^{-2}$ & $217 \mathrm{Fg}^{-1}$ & Wu et al., 2011 \\
\hline $\mathrm{MnCo}_{2} \mathrm{O}_{4.5} @ \mathrm{NiCo}_{2} \mathrm{O}_{4}$ & $3 \mathrm{M} \mathrm{KOH}$ & $1 \mathrm{Ag}^{-1}$ & $325 \mathrm{~F} \mathrm{~g}^{-1}$ & This work \\
\hline
\end{tabular}

All values are derived from characterizations in three-electrode systems.

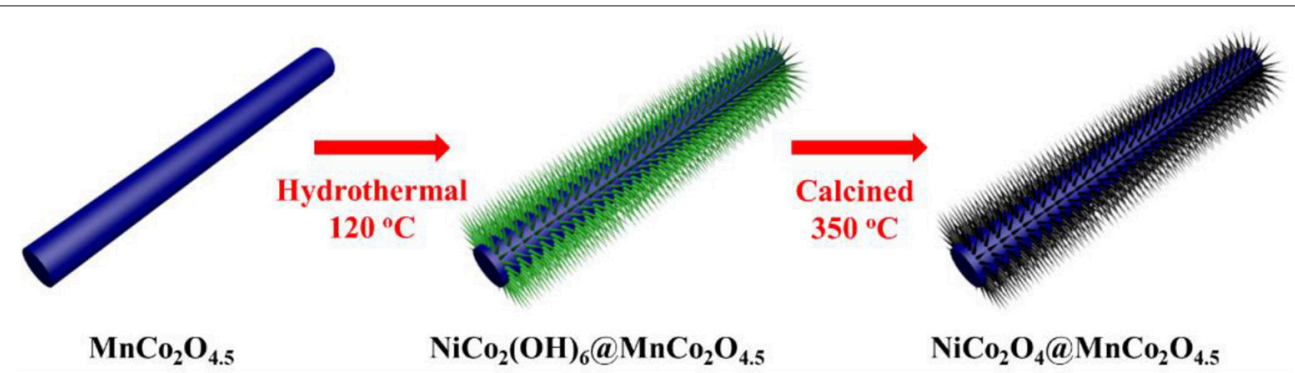

FIGURE 1 | Schematic illustration of the procedure to synthesize $\mathrm{NiCO}_{2} \mathrm{O}_{4} @ \mathrm{MnCo}_{2} \mathrm{O}_{4.5}$ composites.

where $I$ is the operated current (A), $\Delta t$ the discharge time (s), $m$ the mass of active electrode materials $(\mathrm{g})$, and $\Delta V$ the potential window of discharge $(\mathrm{V})$.

\section{RESULTS AND DISCUSSION}

The X-ray diffraction peaks of the prepared products were well-indexed to the cubic phase of $\mathrm{MnCo}_{2} \mathrm{O}_{4.5}$ (JCPDS 320297) (Figure 2A) (Hao et al., 2015). No additional peak for other phase of $\mathrm{MnCo}_{2} \mathrm{O}_{4.5}$ was observed and the sharp and narrow diffraction peaks forecast that the $\mathrm{MnCo}_{2} \mathrm{O}_{4.5}$ microstructures have high crystallinity. The diffraction peaks of the $\mathrm{MnCo}_{2} \mathrm{O}_{4.5} @ \mathrm{NiCo}_{2} \mathrm{O}_{4}$ have minor left shift $\left(0.1^{\circ}\right)$ compared with $\mathrm{MnCo}_{2} \mathrm{O}_{4.5}$ (Figure 2B), which is ascribed the crystallinity of $\mathrm{NiCo}_{2} \mathrm{O}_{4}$ (JCPDS 20-0781) is very similar to $\mathrm{MnCo}_{2} \mathrm{O}_{4.5}$ (Sun et al., 2016; Wang C. et al., 2016), but the lattice constant is tiny bigger than $\mathrm{MnCo}_{2} \mathrm{O}_{4.5} \cdot \mathrm{NiCo}_{2} \mathrm{O}_{4}$ and $\mathrm{MnCo}_{2} \mathrm{O}_{4.5}$ are both spinel structured crystals and have a high degree of lattice matching ( $\sim 0.3 \%$ mis-match). The lattice parameters of $\mathrm{MnCo}_{2} \mathrm{O}_{4.5}$ are $8.08^{*} 8.08^{*} 8.08<90.0 * 90.0^{*} 90.0>$, and $\mathrm{NiCo}_{2} \mathrm{O}_{4}$ $8.11 * 8.11^{*} 8.11<90.0 * 90.0 * 90.0>$ and the Figures $3 \mathbf{A}, \mathbf{B}$ show the crystal structure of $\mathrm{MnCo}_{2} \mathrm{O}_{4.5}$ and $\mathrm{NiCo}_{2} \mathrm{O}_{4}$, respectively. Moreover, in the XRD results the peak intensities of the (311) and (440) planes are higher than others, therefore $\mathrm{NiCo}_{2} \mathrm{O}_{4}$ is most likely to grow along the (311) and (440) planes and completely coherent with $\mathrm{MnCo}_{2} \mathrm{O}_{4.5}$ at the (311) and
(440) planes. Figures 3C,D shows the possible epitaxial growth patterns of $\mathrm{MnCo}_{2} \mathrm{O}_{4.5} @ \mathrm{NiCo}_{2} \mathrm{O}_{4}$ as mentioned above.

Thermogravimetric (TGA) and differential scanning calorimetry (DSC) were performed at a $10^{\circ} \mathrm{C} \mathrm{min}^{-1}$ heating rate to investigate the thermal properties (Figure 2C). The TGA-DSC curve of the Ni-Co hydroxide on $\mathrm{MnCo}_{2} \mathrm{O}_{4.5}$ is shown in Figure 2C. The evaporation of the physically adsorbed water resulted in the weight loss (about $3 \%$ ) till $280^{\circ} \mathrm{C}$. And the followed $17 \%$ weight loss between 280 and $400^{\circ} \mathrm{C}$ is most likely to be caused by the crystalliferous water loss and the decomposition of Ni-Co hydroxide. There is no obvious weight loss after $400^{\circ} \mathrm{C}$. Based on these findings, $350^{\circ} \mathrm{C}$ is chosen and believed to be sufficient for calcination treatment of hydroxides.

SEM was adopted to investigate the morphologies of asprepared composites. As shown in Figure S1, the $\mathrm{MnCo}_{2} \mathrm{O}_{4.5}$ nanowires exhibit fibrous morphologies with smooth surface. The length $\mathrm{MnCo}_{2} \mathrm{O}_{4.5}$ nanowires are several micrometers and the average diameter is about $300 \sim 500 \mathrm{~nm}$. Figures 4A,B shows that $\mathrm{NiCo}_{2} \mathrm{O}_{4}$ nanowires with smaller diameter are successfully and uniformly grown on the surface of $\mathrm{MnCo}_{2} \mathrm{O}_{4.5}$ nanowires. When the reaction time increases from 6 to $12 \mathrm{~h}$, dense $\mathrm{NiCo}_{2} \mathrm{O}_{4}$ nanowires are observed (Figure 4B) with more nanowires locating within the unit area of $\mathrm{MnCo}_{2} \mathrm{O}_{4.5}$ surface. The two insets in Figures $4 \mathbf{A}, \mathbf{B}$ are the images of corresponding samples at higher magnifications. The EDS mapping demonstrates the uniform distribution of $\mathrm{Mn}, \mathrm{Ni}$, 

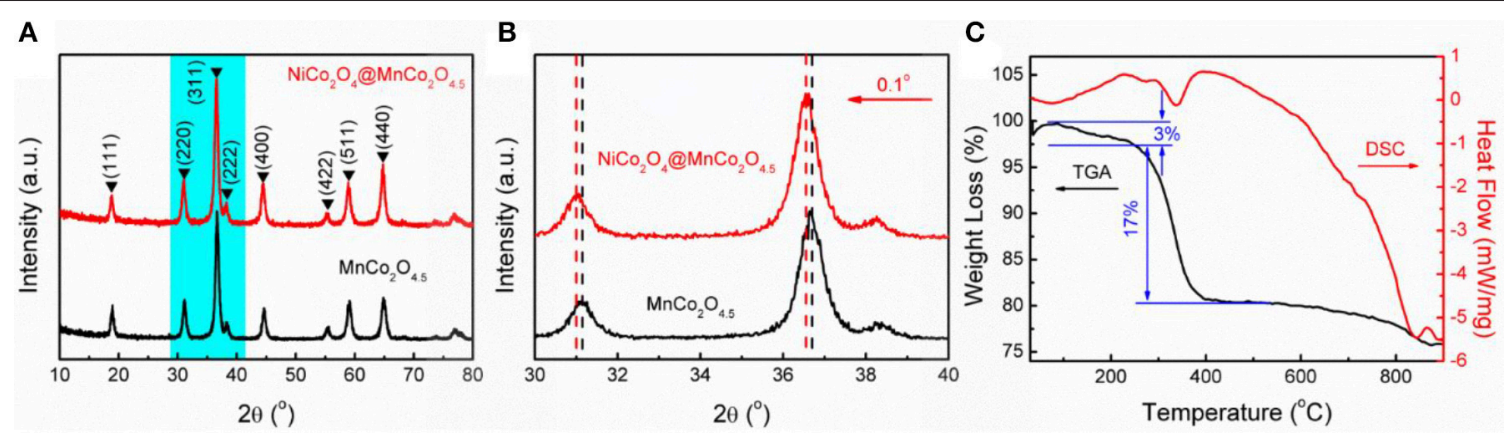

FIGURE 2 | (A) XRD patterns of $\mathrm{MnCo}_{2} \mathrm{O}_{4.5}$ nanowires and $\mathrm{MnCo}_{2} \mathrm{O}_{4.5} @ \mathrm{NiCO}_{2} \mathrm{O}_{4}$ composites. (B) The enlarged XRD patterns at the 2 $\theta$ of 30-40. (C) TGA-DSC curves of $\mathrm{Ni}$-Co hydroxide@ $\mathrm{MnCO}_{2} \mathrm{O}_{4.5}$ composites.

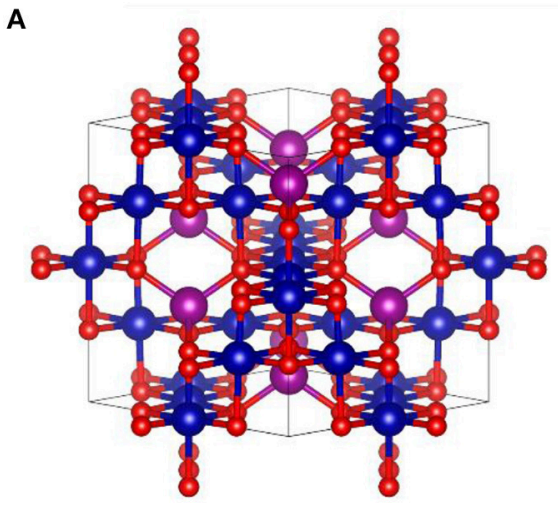

C

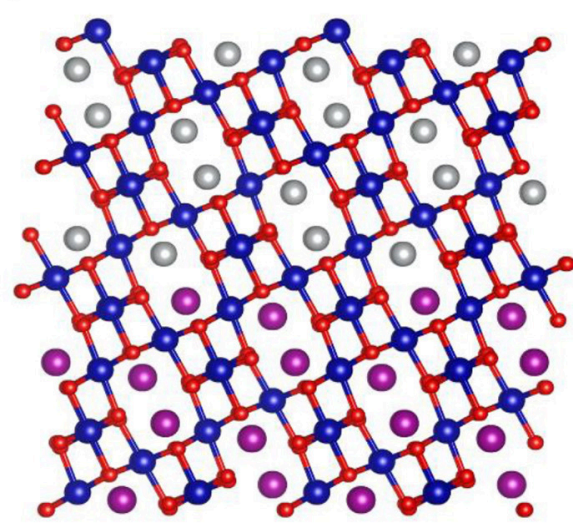

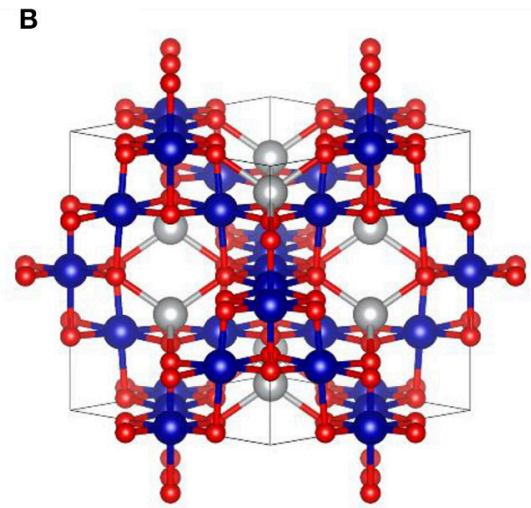

D

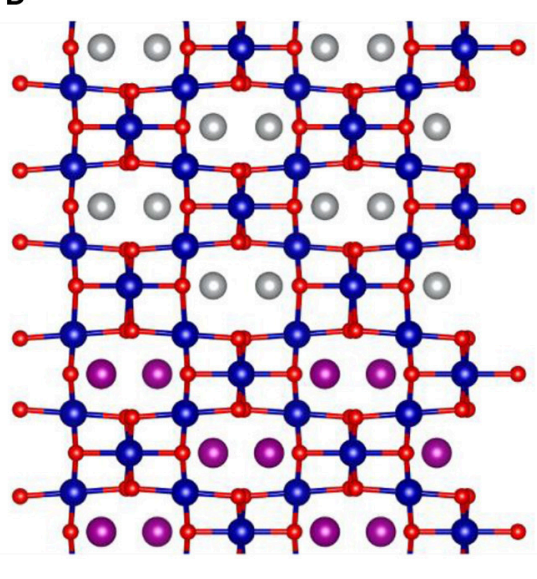

$\odot \mathrm{O} \odot \mathrm{Co} \odot \mathrm{Mn} \odot \mathrm{Ni}$

FIGURE 3 | The schematic diagram of $\mathrm{MnCO}_{2} \mathrm{O}_{4.5}$ (A) and $\mathrm{NiCO}_{2} \mathrm{O}_{4}$ (B) crystal structure. Structure description for possible epitaxial growth patterns of $\mathrm{MnCO}_{2} \mathrm{O}_{4.5} @ \mathrm{NiCO}_{2} \mathrm{O}_{4}$ (C) $\mathrm{NiCO}_{2} \mathrm{O}_{4}$ growing along (311) plane of $\mathrm{MnCO}_{2} \mathrm{O}_{4.5}$; (D) $\mathrm{NiCO}_{2} \mathrm{O}_{4}$ growing along (440) plane of $\mathrm{MnCO}_{2} \mathrm{O}_{4.5}$.

Co, and O (Figures 4C,D), suggesting successful fabrication of well-distributed $\mathrm{MnCo}_{2} \mathrm{O}_{4.5} @ \mathrm{NiCo}_{2} \mathrm{O}_{4}$ nanowires and forming the core-shell structure. Furthermore, the detailed structural information of the coated $\mathrm{NiCo}_{2} \mathrm{O}_{4.5}$ shell nanowires was collected by TEM at different magnifications (Figures 5A,B).
The primary $\mathrm{NiCo}_{2} \mathrm{O}_{4}$ nanowires have a diameter of $50 \sim 80 \mathrm{~nm}$. High-resolution TEM (HRTEM, Figure 5B) image of the $\mathrm{NiCo}_{2} \mathrm{O}_{4}$ nanowires reveal well-resolved lattice fringe having an inter-planar spacing of 0.20 and $0.47 \mathrm{~nm}(\mathbf{b}-\mathbf{1})$, which are wellconsistent with the distance of the (400) and (111) plane of 

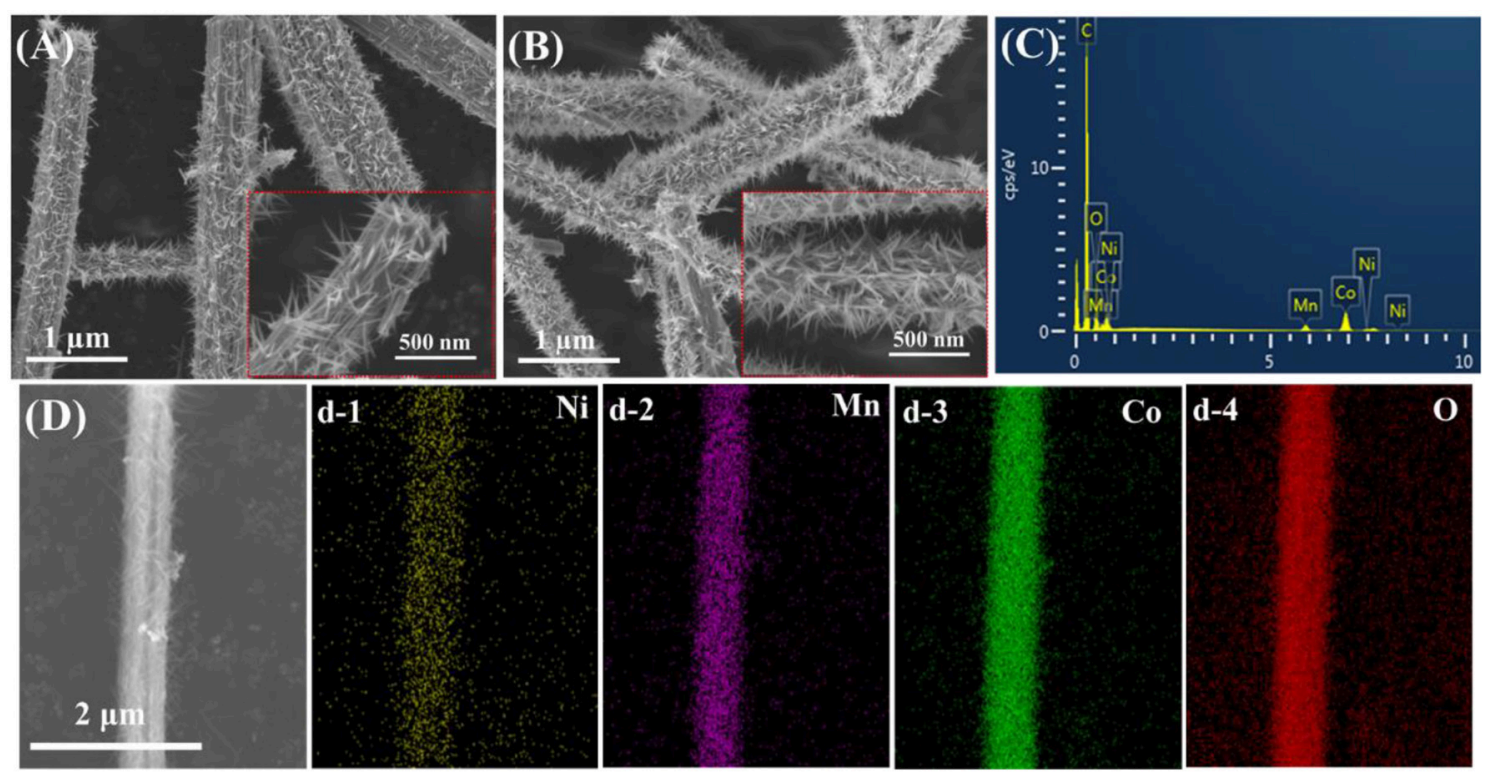

FIGURE 4 | SEM images of (A) $\mathrm{MnCo}_{2} \mathrm{O}_{4.5} @ \mathrm{NiCO}_{2} \mathrm{O}_{4}-6 \mathrm{~h}$ and (B) $\mathrm{MnCo}_{2} \mathrm{O}_{4.5} @ \mathrm{NiCo}_{2} \mathrm{O}_{4}-12 \mathrm{~h}$; (C,D) EDS mapping results from $\mathrm{MnCo}_{2} \mathrm{O}_{4.5} @ \mathrm{NiCO}_{2} \mathrm{O}_{4}$.

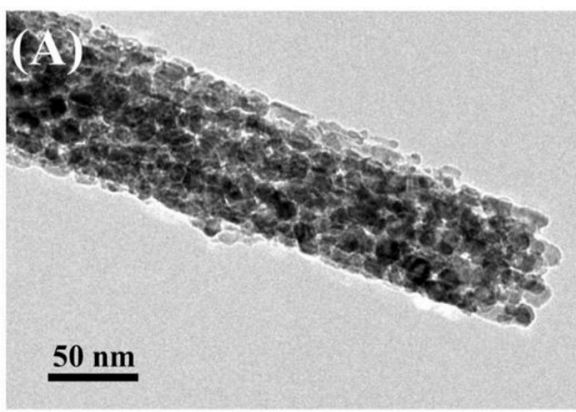

(C)

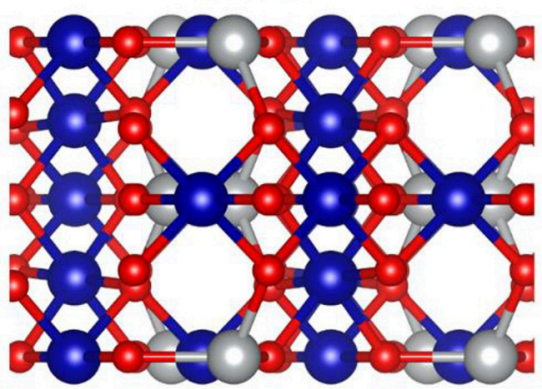

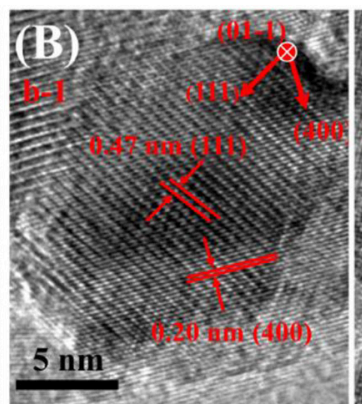

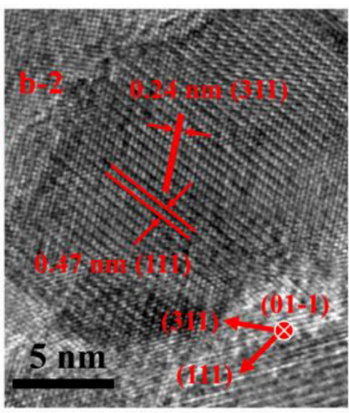

(D) (01-1)

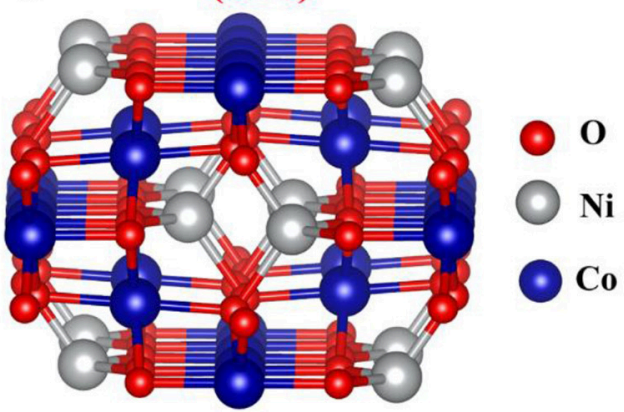

FIGURE 5 | (A) TEM and (B) HRTEM images of the shell $\mathrm{NiCO}_{2} \mathrm{O}_{4}$ nanowires (b-1 and $\mathbf{b}-\mathbf{2}$ are the different site of the NiCo${ }_{2} \mathrm{O}_{4}$ nanowires); (C,D) the schematic diagram of $\mathrm{NiCO}_{2} \mathrm{O}_{4}$ with (01-1) facets exposed.

$\mathrm{NiCo}_{2} \mathrm{O}_{4}$, respectively. And the (b-2) shows inter-planar spacing of 0.24 and $0.47 \mathrm{~nm}$, which represent the (311) and (111) facet of $\mathrm{NiCo}_{2} \mathrm{O}_{4}$. Therefore, these results about the crystal structure and facets illustrate that the (01-1) facets of $\mathrm{NiCo}_{2} \mathrm{O}_{4}$ are exposed (Figures 5C,D).
XPS measurement was employed to reveal the composition and surface chemical states of the $\mathrm{MnCo}_{2} \mathrm{O}_{4.5} @ \mathrm{NiCo}_{2} \mathrm{O}_{4}$, and the detailed results are shown in Figure 6. It can be clearly seen from survey spectrum (Figure 6A) that the $\mathrm{MnCo}_{2} \mathrm{O}_{4.5} @ \mathrm{NiCo}_{2} \mathrm{O}_{4}$ consists of $\mathrm{O}, \mathrm{Ni}, \mathrm{Co}$, and $\mathrm{Mn}$ elements, being consistent with 

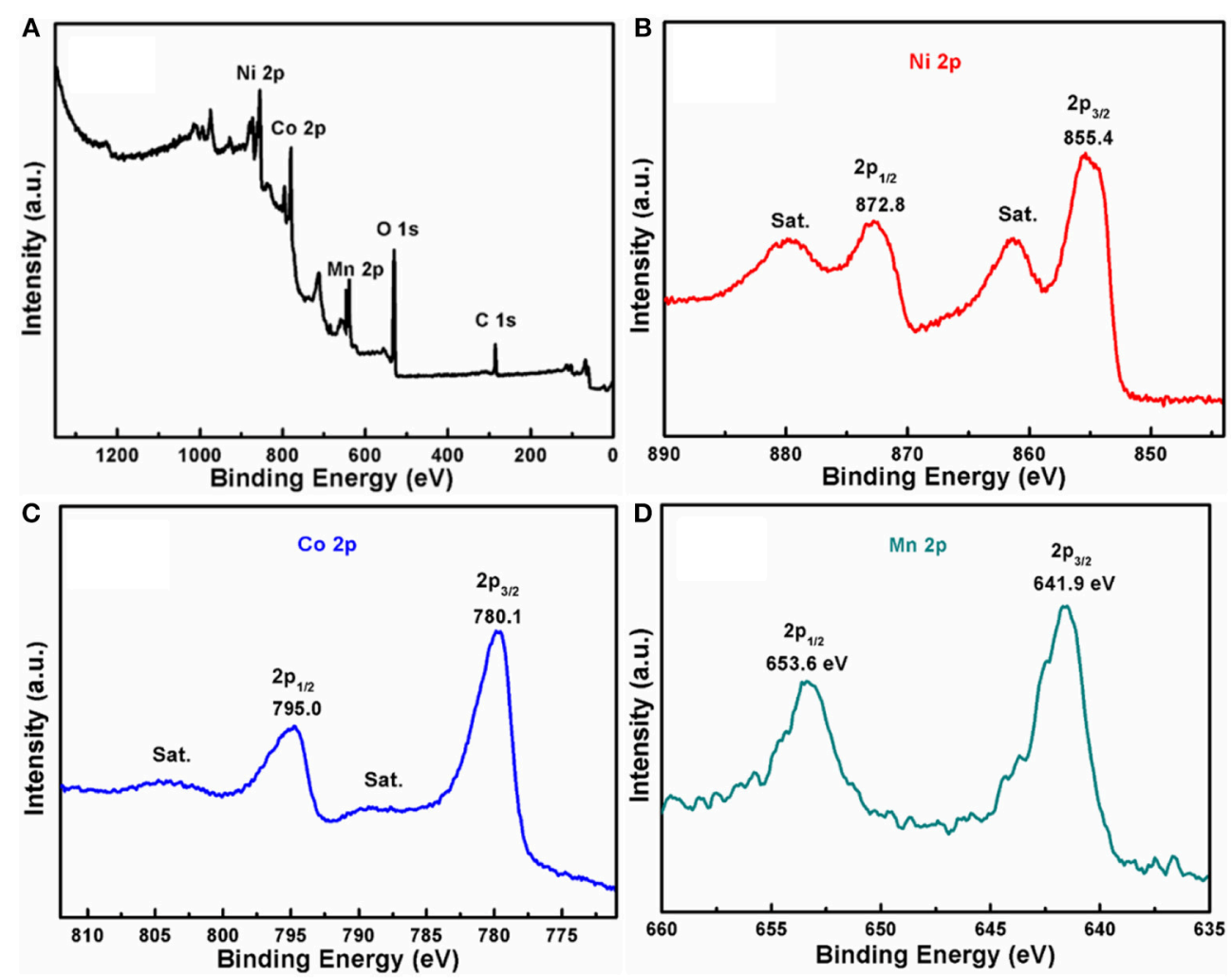

FIGURE 6 | (A) XPS survey spectrum; (B-D) high-resolution Ni 2p, Co 2p, and Mn 2p XPS spectra of the as-made $\mathrm{MnCo}_{2} \mathrm{O}_{4.5} @ \mathrm{NiCO}_{2} \mathrm{O}_{4}$.

EDS results (Figure 3D). The high resolution XPS spectrum of $\mathrm{Ni} 2 \mathrm{p}$ (Figure 6B) reveals that two obvious shakeup satellites (indicated as "Sat.") are close to two spin orbit doublets at 855.4 and $872.8 \mathrm{eV}$, which represents the $\mathrm{Ni} 2 \mathrm{p}_{3 / 2}$ and $\mathrm{Ni} 2 \mathrm{p}_{1 / 2}$ splitting in $\mathrm{Ni}^{2+}$ chemical state, respectively (Hareesh et al., 2016; Sun et al., 2016; Wang et al., 2017; Zhang et al., 2018b). In the Co 2p XPS spectrum, the spin orbit splitting to the Co $2 \mathrm{p}_{1 / 2}(795.0 \mathrm{eV})$ and $\mathrm{Co} 2 \mathrm{p}_{3 / 2}(780.1 \mathrm{eV})$ reaches $14.9 \mathrm{eV}$ (Figure 6C), indicating the co-existence of $\mathrm{Co}^{2+}$ and $\mathrm{Co}^{3+}$ in $\mathrm{MnCo}_{2} \mathrm{O}_{4.5} @ \mathrm{NiCo}_{2} \mathrm{O}_{4}$ (Wu et al., 2015; Liu et al., 2017; Wang et al., 2017). Likewise, the peaks of $\mathrm{Mn}$ element locating at $641.9 \mathrm{eV}$ and $653.6 \mathrm{eV}$ in Figure $6 \mathrm{D}$ consistent with $\mathrm{Mn} 2 \mathrm{p}_{3 / 2}$ and $\mathrm{Mn} 2 \mathrm{p}_{1 / 2}$, respectively (Hui et al., 2016; Liu et al., 2017; Zhao et al., 2018; Zhu et al., 2018).

The electrochemical performance of the samples was analyzed by $\mathrm{CV}$ and GCD measurements. Figures 7A,B illustrates the $\mathrm{CV}$ and GCD curves of the three different electrodes at the same scan rate $\left(100 \mathrm{mV} \mathrm{S}^{-1}\right)$ and current density ( $1 \mathrm{~A} \mathrm{~g}^{-1}$ ), respectively. $\mathrm{MnCo}_{2} \mathrm{O}_{4.5} @ \mathrm{NiCo}_{2} \mathrm{O}_{4}-12 \mathrm{~h}$ displays better rate performance with lower distortion compared with $\mathrm{MnCo}_{2} \mathrm{O}_{4.5} @ \mathrm{NiCo}_{2} \mathrm{O}_{4}$-6h (Figure 7B). This is possibly due to the mass increasing of $\mathrm{NiCo}_{2} \mathrm{O}_{4}$ and the lower mass transport resistance within smaller interstitial regimes between the electrolyte and electrode materials. In Figure 7C, the $\mathrm{CV}$ curves of $\mathrm{MnCo}_{2} \mathrm{O}_{4.5} @ \mathrm{NiCo}_{2} \mathrm{O}_{4}-12 \mathrm{~h}$ exhibit a quasireversible oxidative and reductive shape, indicating an ideal capacitance characteristic and a good reversibility of the architectures with good electronic conductivity and low internal resistance (Zhu et al., 2015; Hui et al., 2016; Sun et al., 2016; Wang et al., 2017). With the increment of scan rates, slight distortion of curves is observed, implying the favorable rate ability. The galvanostatic charge-discharge results of $\mathrm{MnCo}_{2} \mathrm{O}_{4.5} @ \mathrm{NiCo}_{2} \mathrm{O}_{4}-12 \mathrm{~h}$ are presented in Figure 7D. Similarly, pseudo-capacitive behaviors are observed and the shape of GCD curves is not triangular ones which are believed to be pure electrical double layer capacitors (EDLCs).

The symmetrical shapes of the charge side and discharge side indicate the good reversibility of the synthesized composites. The $\mathrm{MnCo}_{2} \mathrm{O}_{4.5} @ \mathrm{NiCo}_{2} \mathrm{O}_{4}-12 \mathrm{~h}$ composites (Figure 7D) have a higher specific capacitance of $325 \mathrm{~F} \mathrm{~g}^{-1}$ $\left(146 \mathrm{C} \mathrm{g}^{-1}\right)$ than that of $\mathrm{MnCo}_{2} \mathrm{O}_{4.5} @ \mathrm{NiCo}_{2} \mathrm{O}_{4}-6 \mathrm{~h}[162.5 \mathrm{~F}$ $\mathrm{g}^{-1}\left(73 \mathrm{C}^{-1}\right)$, Figure $\left.7 \mathrm{~B}\right]$ at the same discharge current density $\left(1 \mathrm{~A} \mathrm{~g}^{-1}\right)$, which is owning to its higher mass ratio of active $\mathrm{NiCo}_{2} \mathrm{O}_{4}$. Compared with pristine $\mathrm{MnCo}_{2} \mathrm{O}_{4.5}$, the electrochemical performance of synthesized core-shell composites is greatly improved based on the following two effects: $\mathrm{MnCo}_{2} \mathrm{O}_{4.5} @ \mathrm{NiCo}_{2} \mathrm{O}_{4}-12 \mathrm{~h}$ has larger accessible surface area from loose $\mathrm{NiCo}_{2} \mathrm{O}_{4}$ shell layer which is built with isolated free-standing nanowires with smaller diameters; and shorter ion diffusion distance from smaller free-standing $\mathrm{NiCo}_{2} \mathrm{O}_{4}$ nanowires and interstitial regime between nanowires as well. 

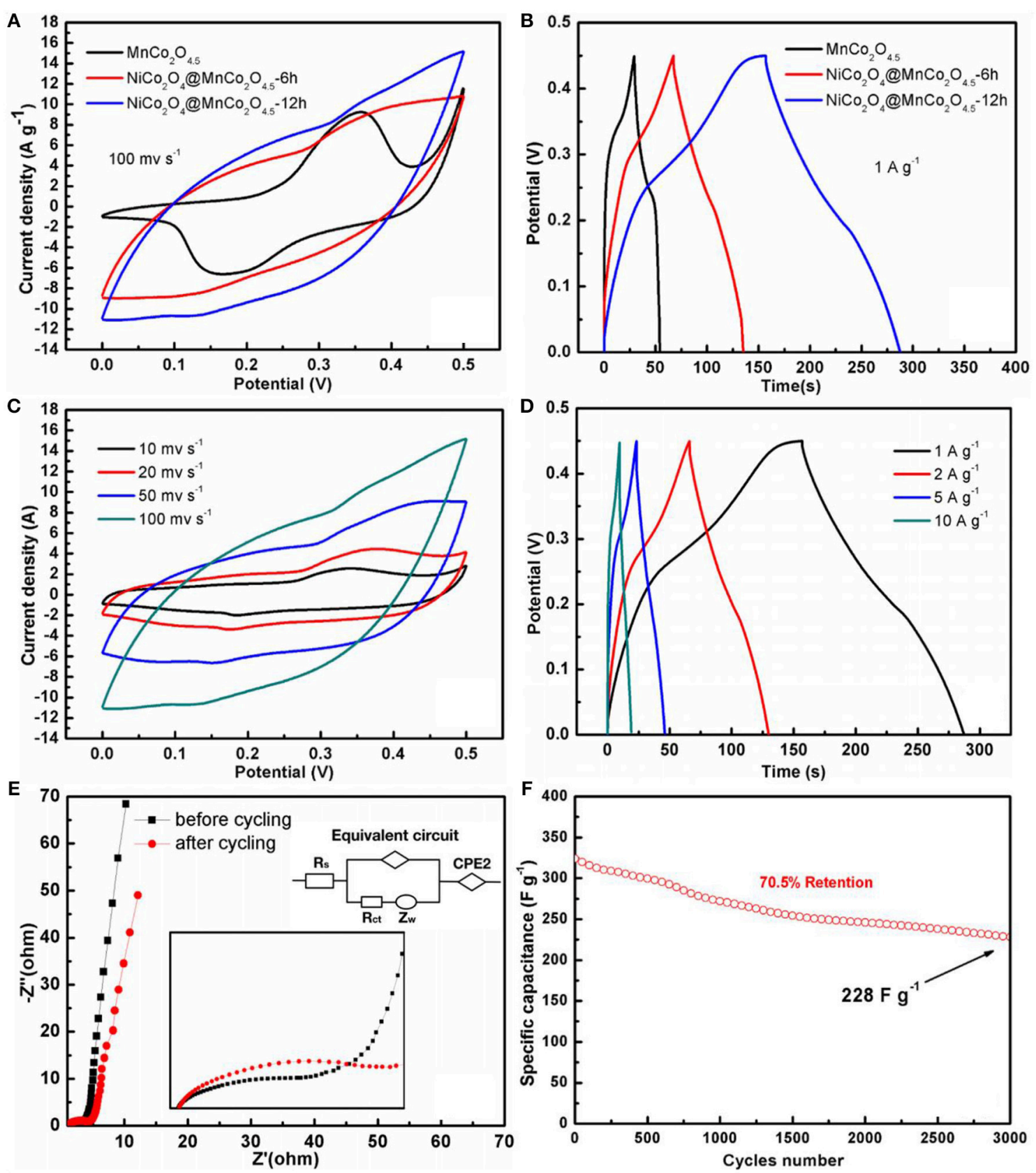

FIGURE 7 | (A,B) CV and GCD curves of the samples; (C) CV curves of $\mathrm{MnCo}_{2} \mathrm{O}_{4.5} @ \mathrm{NiCO}_{2} \mathrm{O}_{4}-12 \mathrm{~h}$ sample at different scan rates; (D) GCD curves of $\mathrm{MnCo}_{2} \mathrm{O}_{4.5} @ \mathrm{NiCo}_{2} \mathrm{O}_{4}-12 \mathrm{~h}$ sample at different current densities. (E) Electrochemical impedance spectrum of $\mathrm{MnCo}_{2} \mathrm{O}_{4.5} @ \mathrm{NiCo}_{2} \mathrm{O}_{4}-12 \mathrm{~h}$ sample before and after cycling. (Inset) Magnification of the electrochemical impedance spectrum at low frequency (F) Cycling performance of $\mathrm{MnCo}_{2} \mathrm{O}_{4.5} @ \mathrm{NiCO}_{2} \mathrm{O}_{4}-12 \mathrm{~h}$ at the current density of $1 \mathrm{~A} \mathrm{~g}^{-1}$.

Figure 7E depicts the electrical impedance spectroscopy (EIS) of the composites before and after 3,000 cycling tests. The inset is magnified spectrum at low impedance region. The impedance spectrum is a semicircle parts at the high frequency and a linear curve at the low frequency. The intercept of the curves on the real axis reveals the total value of the ohmic resistance of electrolyte added with the resistance of the active materials. After cycling test, the radius of the semicircle increased obviously while first intercept and slope of the linear part change slightly. The apparent increasing of semicircle radius means more difficult for charge transfer of active species inside the electrode materials. The minor increasing of first intercept and decreasing of slope indicate higher contacting impedance and mass transport resistance after cycling tests. All the changes 
are derived from the potential structural damage of electrode materials during cycling tests. However, the overall capacitance retention is still up to $70.5 \%$ after 3,000 cycling tests (Figure 7F), which means this damage over cycling is at low level. This good cycling ability of $\mathrm{MnCo}_{2} \mathrm{O}_{4.5} @ \mathrm{NiCo}_{2} \mathrm{O}_{4}$ is attributed to its unique one-dimensional structure. The one-dimensional structure has much free spaces between the nanowires, being able to accommodate the volume change of the materials during cycling and maintain the activity of the materials at high level.

\section{CONCLUSIONS}

The $\mathrm{MnCo}_{2} \mathrm{O}_{4.5} @ \mathrm{NiCo}_{2} \mathrm{O}_{4}$ composites with core-shell structure has been successfully synthesized with a facile and green hydrothermal method for high performance supercapacitors. The nanostructures, morphology and electrochemical performance of the composites are fully demonstrated. The $\mathrm{MnCo}_{2} \mathrm{O}_{4.5} @ \mathrm{NiCo}_{2} \mathrm{O}_{4}$ composites exhibit remarkable capacitive performance with maximum capacitances of $325 \mathrm{~F} \mathrm{~g}^{-1}$ (146 C $\left.\mathrm{g}^{-1}\right)$ and retention $70.5 \%$ of the initial capacitance after 3,000 cycles at $1 \mathrm{~A} \mathrm{~g}^{-1}$. This excellent electrochemical performance of $\mathrm{MnCo}_{2} \mathrm{O}_{4.5} @ \mathrm{NiCo}_{2} \mathrm{O}_{4}$ composites are attributed to the unique core-shell double spinel structures with shell built of isolated free-standing nanowires. The free spaces between nanowires are able to provide channels for mass transfer of active species and accommodate the volume change during cycling.

\section{REFERENCES}

Dai, S., Liu, Z., Zhao, B., Zeng, J., Hu, H., Zhang, Q., et al. (2018). A highperformance supercapacitor electrode based on $\mathrm{N}$-doped porous graphene. J. Power Sources 387, 43-48. doi: 10.1016/j.jpowsour.2018.03.055

Dai, S., Zhao, B., Qu, C., Chen, D., Dang, D., Song, B., et al. (2017). Controlled synthesis of three-phase NixSy/rGO nanoflake electrodes for hybrid supercapacitors with high energy and power density. Nano Energy 33, 522-531. doi: 10.1016/j.nanoen.2017.01.056

Hao, P., Zhao, Z., Li, L., Tuan, C.-C., Li, H., Sang, Y., et al. (2015). The hybrid nanostructure of $\mathrm{MnCo}_{2} \mathrm{O}_{4.5}$ nanoneedle/carbon aerogel for symmetric supercapacitors with high energy density. Nanoscale 7, 14401-14412. doi: 10.1039/c5nr04421a

Hareesh, K., Shateesh, B., Joshi, R. P., Dahiwale, S. S., Bhoraskar, V. N., Haram, S. K., et al. (2016). PEDOT: PSS wrapped $\mathrm{NiFe}_{2} \mathrm{O}_{4} / \mathrm{rGO}$ tertiary nanocomposite for the super-capacitor applications. Electrochim. Acta 201, 106-116. doi: 10.1016/j.electacta.2016.03.205

Hui, K. N., Hui, K. S., Tang, Z., Jadhav, V. V., and Xia, Q. X. (2016). Hierarchical chestnut-like $\mathrm{MnCo}_{2} \mathrm{O}_{4}$ nanoneedles grown on nickel foam as binder-free electrode for high energy density asymmetric supercapacitors. J. Power Sources 330, 195-203. doi: 10.1016/j.jpowsour.2016.08.116

Kuang, M., Zhang, W., Guo, X. L., Yu, L., and Zhang, Y. X. (2014). Template-free and large-scale synthesis of hierarchical dandelion-like $\mathrm{NiCo}_{2} \mathrm{O}_{4}$ microspheres for high-performance supercapacitors. Ceram. Int. 40, 10005-10011. doi: 10.1016/j.ceramint.2014.02.099

Li, F., Li, G., Chen, H., Jia, J. Q., Dong, F., Hu, Y. B., et al. (2015). Morphology and crystallinity-controlled synthesis of manganese cobalt oxide/manganese dioxides hierarchical nanostructures for high-performance supercapacitors. J. Power Sources 296, 86-91. doi: 10.1016/j.jpowsour.2015.07.029

Li, W., Xu, K., Song, G., Zhou, X., Zou, R., Yang, J., et al. (2014). Facile synthesis of porous $\mathrm{MnCo}_{2} \mathrm{O}_{4.5}$ hierarchical architectures for high-

\section{AUTHOR CONTRIBUTIONS}

YXZ and YSY designed the research. WCH, XLL, and XYL performed the experiments. NL and TL carried out the partial experimental characterization. All authors incorporated in the discussion of experimental results.

\section{ACKNOWLEDGMENTS}

We gratefully thank the financial support of the Fundamental Research Funds for the Central Universities (2018CDYJSY0055 and 106112017CDJXSYY0001), the National Natural Science Foundation of China (Grant no. 21576034), the key scientific and technological projects of Chongqing Municipal Education Commission (KJZD-K201800801), Joint Funds of the National Natural Science Foundation of China-Guangdong (Grant no. U1801254), the project funded by Chongqing Special Postdoctoral Science Foundation (XmT2018043), and Technological projects of Chongqing Municipal Education Commission (KJZDK201800801). We also thank the Electron Microscopy Center of Chongqing University for materials characterizations.

\section{SUPPLEMENTARY MATERIAL}

The Supplementary Material for this article can be found online at: https://www.frontiersin.org/articles/10.3389/fchem. 2018.00661/full\#supplementary-material

rate supercapacitors. CrystEngComm 16, 2335-2339. doi: 10.1039/c3ce4 2581a

Lim, Y.-G., Park, M.-S., Kim, K. J., Jung, K.-S., Kim, J. H., Shahabuddin, M., et al. (2015). Incorporation of conductive polymer into soft carbon electrodes for lithium ion capacitors. J. Power Sources 299, 49-56. doi: 10.1016/j.jpowsour.2015.08.083

Liu, J.-L., Fan, L.-Z., and Qu, X. (2012). Low temperature hydrothermal synthesis of nano-sized manganese oxide for supercapacitors. Electrochim. Acta 66, 302-305. doi: 10.1016/j.electacta.2012.01.095

Liu, Q., Hong, X. D., Zhang, X., Wang, W., Guo, W. X., Liu, X. Y., et al. (2019). Hierarchically structured $\mathrm{Co}_{9} \mathrm{~S}_{8} @ \mathrm{NiCo}_{2} \mathrm{O}_{4}$ nanobrushes for highperformance flexible asymmetric supercapacitors. Chem. Eng. J. 356, 985-993. doi: 10.1016/j.cej.2018.09.095

Liu, S., Lee, S. C., Patil, U., Shackery, I., Kang, S., Zhang, K., et al. (2017). Hierarchical MnCo-layered double hydroxides@Ni(OH $)_{2}$ core-shell heterostructures as advanced electrodes for supercapacitors. J. Mater. Chem. A 5, 1043-1049. doi: 10.1039/c6ta07842g

Lukatskaya, M. R., Dunn, B., and Gogotsi, Y. (2016). Multidimensional materials and device architectures for future hybrid energy storage. Nat. Commun. 7:12647. doi: $10.1038 /$ ncomms 12647

Miller, J. R., and Simon, P. (2008). Materials science-Electrochemical capacitors for energy management. Science 321, 651-652. doi: 10.1126/science.1158736

Nam, I., Kim, G.-P., Park, S., Park, J., Kim, N. D., and Yi, J. (2012). Fabrication and design equation of film-type large-scale interdigitated supercapacitor chips. Nanoscale 4, 7350-7353. doi: 10.1039/c2nr31961f

Niu, Z., Zhang, L., Liu, L., Zhu, B., Dong, H., and Chen, X. (2013). All-solidstate flexible ultrathin micro-supercapacitors based on graphene. Adv. Mater. 25, 4035-4042. doi: 10.1002/adma.201301332

Parveen, N., Al-Jaafari, A. I., and Han, J. I. (2019). Robust cyclic stability and highrate asymmetric supercapacitor based on orange peel-derived nitrogen-doped porous carbon and intercrossed interlinked urchin-like $\mathrm{NiCo}_{2} \mathrm{O}_{4} @ 3 \mathrm{DNF}$ 
framework. Electrochim. Acta 293, 84-96. doi: 10.1016/j.electacta.2018.0 8.157

Qiu, W. D., Xiao, H. B., Yu, M. H., Li, Y., and Lu, X. H. (2018). Surface modulation of $\mathrm{NiCo}_{2} \mathrm{O}_{4}$ nanowire arrays with significantly enhanced reactivity for ultrahigh-energy supercapacitors. Chem. Eng. J. 352, 996-1003. doi: 10.1016/j.cej.2018.04.118

Qu, C., Zhao, B., Jiao, Y., Chen, D., Dai, S., Deglee, B. M., et al. (2017), Functionalized bimetallic hydroxides derived from metal-organic frameworks for high-performance hybrid supercapacitor with exceptional cycling stability. ACS Energy Lett. 2, 1263-1269. doi: 10.1021/acsenergylett.7b00265

Simon, P., and Gogotsi, Y. (2008). Materials for electrochemical capacitors. Nat. Mater. 7, 845-854. doi: 10.1038/nmat2297

Sun, D. S., Li, Y. H., Wang, Z. Y., Cheng, X. P., Jaffer, S., and Zhang, Y. F. (2016). Understanding the mechanism of hydrogenated $\mathrm{NiCo}_{2} \mathrm{O}_{4}$ nanograss supported on $\mathrm{Ni}$ foam for enhanced-performance supercapacitors. J. Mater. Chem. A 4, 5198-5204. doi: 10.1039/c6ta00928j

Sun, J., Zeng, Q., Lv, R., Lv, W., Yang, Q.-H., Amal, R., et al. (2018). A Li-ion sulfur full cell with ambient resistant Al-Li alloy anode. Energy Storage Mater. 15, 209-217. doi: 10.1016/j.ensm.2018.04.003

Wang, C., Zhou, E., Deng, X., Shao, M., Huang, J., Wei, X., et al. (2016). Threedimensionally porous $\mathrm{NiCo}_{2} \mathrm{O}_{4}$ nanoneedle arrays for high performance supercapacitor. Sci. Adv. Mater. 8, 1298-1304. doi: 10.1166/sam.201 6.2725

Wang, K., Xu, J., Lu, A., Shi, Y., and Lin, Z. (2016). Coordination polymer template synthesis of hierarchical $\mathrm{MnCo}_{2} \mathrm{O}_{4.5}$ and $\mathrm{MnNi}_{6} \mathrm{O}_{8}$ nanoparticles for electrochemical capacitors electrode. Solid State Sci. 58, 70-79. doi: 10.1016/j.solidstatesciences.2016.06.001

Wang, T., Zhang, S., Yan, X., Lyu, M., Wang, L., Bell, J., et al. (2017). 2methylimidazole-derived $\mathrm{Ni}$-Co layered double hydroxide nanosheets as high rate capability and high energy density storage material in hybrid supercapacitors. ACS Appl. Mater. Interfaces 9, 15510-15524. doi: 10.1021/acsami.7b02987

Wu, C., Cai, J., Zhang, Q., Zhou, X., Zhu, Y., Li, L., et al. (2015). Direct growth of urchin-like $\mathrm{ZnCo}_{2} \mathrm{O}_{4}$ microspheres assembled from nanowires on nickel foam as high-performance electrodes for supercapacitors. Electrochim. Acta 169, 202-209. doi: 10.1016/j.electacta.2015.04.079

Wu, Y. Q., Chen, X. Y., Ji, P. T., and Zhou, Q. Q. (2011). Sol-gel approach for controllable synthesis and electrochemical properties of $\mathrm{NiCo}_{2} \mathrm{O}_{4}$ crystals as electrode materials for application in supercapacitors. Electrochim. Acta 56, 7517-7522. doi: 10.1016/j.electacta.2011.06.101

$\mathrm{Xu}, \quad \mathrm{S}$., and Wang, Z. L. (2011). One-dimensional ZnO nanostructures: solution growth and functional properties.
Nano Res. 4, 1013-1098. doi: 10.1007/s12274-011-0 160-7

Zhang, Q., Chen, H., Luo, L., Zhao, B., Luo, H., Han, X., et al. (2018a). Harnessing the concurrent reaction dynamics in active $\mathrm{Si}$ and $\mathrm{Ge}$ to achieve high performance lithium-ion batteries. Energy Environ. Sci. 11, 669-681. doi: 10.1039/c8ee00239h

Zhang, Q., Liu, Z., Zhao, B., Cheng, Y., Zhang, L., Wu, H.-H., et al. (2018b). Design and understanding of dendritic mixed-metal hydroxide nanosheets@N-doped carbon nanotube array electrode for highperformance asymmetric supercapacitors. Energy Storage Mater.16, 632-645. doi: 10.1016/j.ensm.2018.06.026

Zhao, B. T., Zhang, L., Zhang, Q. B., Chen, D. C., Cheng, Y., Deng, X., et al. (2018). Rational design of nickel hydroxide-based nanocrystals on graphene for ultrafast energy storage. Adv. Energy Mater. 8:1702247. doi: 10.1002/aenm.201702247

Zhao, L., Fan, L.-Z., Zhou, M.-Q., Guan, H., Qiao, S., Antonietti, M., et al. (2010). Nitrogen-containing hydrothermal carbons with superior performance in supercapacitors. Adv. Mater. 22, 5202-5206. doi: 10.1002/adma.201002647

Zheng, Z., Zao, Y., Zhang, Q., Cheng, Y., Chen, H., Zhang, K., et al. (2018). Robust erythrocyte-like $\mathrm{Fe}_{2} \mathrm{O}_{3} @$ carbon with yolk-shell structures as highperformance anode for lithium ion batteries. Chem. Eng. J. 347, 563-573. doi: 10.1016/j.cej.2018.04.119

Zhu, C., Wen, D., Leubner, S., Oschatz, M., Liu, W., Holzschuh, M., et al. (2015). Nickel cobalt oxide hollow nanosponges as advanced electrocatalysts for the oxygen evolution reaction. Chem. Commun. 51, 7851-7854. doi: $10.1039 / \mathrm{c} 5 \mathrm{cc} 01558 \mathrm{~h}$

Zhu, S., Li, L., Liu, J., Wang, H., Wang, T., Zhang, Y., et al. (2018). Structural directed growth of ultrathin parallel birnessite on beta- $\mathrm{MnO}_{2}$ for high-performance asymmetric supercapacitors. ACS Nano 12, 1033-1042. doi: 10.1021/acsnano.7b03431

Conflict of Interest Statement: The authors declare that the research was conducted in the absence of any commercial or financial relationships that could be construed as a potential conflict of interest.

Copyright (C) 2019 Huo, Liu, Yuan, Li, Lan, Liu and Zhang. This is an open-access article distributed under the terms of the Creative Commons Attribution License (CC $B Y)$. The use, distribution or reproduction in other forums is permitted, provided the original author(s) and the copyright owner(s) are credited and that the original publication in this journal is cited, in accordance with accepted academic practice. No use, distribution or reproduction is permitted which does not comply with these terms. 